Tohoku J. exp. Med., 1968, 96, 37-43

\title{
Strychnine-sensitive and -insensitive Inhibitions in Cat's Retina
}

\author{
Shingo Chu \\ Department of Physiology (Prof. K. Tasaki), \\ Tohoku University School of Medicine, Sendai
}

\begin{abstract}
Effects of strychnine on intraretinal inhibition were investigated by recording unitary discharges from the optic tract fibers. Units were classed as on, off and onoff according to their discharge patterns in response to diffuse illumination of the retina. Strychnine enhanced the firing rate of spontaneous discharge in the dark. 'On' inhibition of an off unit was greatly suppressed by strychnine, whereas 'off' inhibition of an on unit was not affected to an appreciable extent. The latter, however, was suppressed by picrotoxin. This difference was discussed in the light of the recent concept of inhibitory mechanisms and also of morphological findings on synapses in the inner plexiform layer.
\end{abstract}

In recent literatures two different types of intraretinal inhibitory mechanisms have been differentiated, namely postsynaptic and presynaptic inhibitions. Eccles and his collaborators have proposed that these two inhibitory mechanisms may be distinguished from each other on the basis of pharmacological properties. ${ }^{12}$ In the spinal cord, strychnine exerts a powerful depressive action upon postsynaptic inhibition, but has no appreciable action on presynaptic inhibition, while picrotoxin depresses presynaptic inhibition with its ineffectiveness on postsynaptic inhibition.

Recently, Kidd ${ }^{3}$ and Dowling and Boycott ${ }^{4}$ have reported axo-axonic synapses in the inner plexiform layer of the vertebrate retina. Such synapses have been assumed to be a morphological entity for presynaptic inbibition.

The aim of this paper is to demonstrate that there are strychnine-sensitive and insensitive inhibitions in the cat's retina

\section{METHODS}

Under ether anesthesia cats were prepared and fixed to a stereotaxic head holder. Pressure points and wound margins were carefully infiltrated with $1 \%$ procain solution, so that general anesthesia might be dispensed with throughout the experiments. The animals were completely immobilized with a continuous infusion of gallamine triethiodide and maintained on artificial ventilation. The pupils were dilated with cycloplegic mydriatic (Mydrin-P), the corneae being protected from drying by plastic contact lenses.

A Sylvanian type $\mathrm{R} 1131 \mathrm{C}$ glow modulator tube was placed in front of the animals

Received for publication, April 17, 1968. 
so that the light beam might be brought to focus on the plane of the animal's pupil, presenting the cat with a Maxwellian view subtending about $15^{\circ}$ of visual angle. The light output was controlled by plate current of a valve $6 \mathrm{~V} 6$ which was driven by squareshaped pulses delivered from an electronic stimulator.

Tungsten microelectrodes were inserted stereotaxically for extracellular recordings of unitary discharges from the optic tract fibers. Spikes were displayed on a cathode ray oscilloscope and also fed into a mean rate recorder after they were reshaped into standard pulses ( 5 volts, $100 \mu \mathrm{sec}$ ). The mean rate recorder essentially consists of a simple RC 'integrating' network and a pen recorder. The time constant 0.1 sec of the RC network was used throughout the experiments. All the data presented in this paper are records by this device.

For administration of strychnine, $0.05 \%$ strychnine-Ringer solution was injected via the superficial vein of the forelimb. The body temperature measured under the scapula was kept at $37.5^{\circ} \mathrm{C}$ by an electric heating pad placed under the body.

\section{Results}

All units were classed as on, off and on-off on the basis of the characteristics of responses to diffuse illumination of the retina. Three types of the units and effects of strychnine thereupon are illustrated in Fig. 1.

An on unit (Fig. 1 A) had a fairly high rate of discharge (about $45 / \mathrm{sec}$ ) in the dark prior to strychnization. At the onset illumination of 30 seconds in duration it showed a steep rise in the firing rate up to more than $150 / \mathrm{sec}$. This initial 'on' discharge subsided to a lower level of discharge during the remaining period of illumination. At the termination of illumination the discharge was temporarily suppressed (post-excitatory inhibition) and then gradually recovered to its original level in the dark. After two control responses were recorded, a small amount of strychnine $(0.12 \mathrm{mg} / \mathrm{kg})$ was injected intravenously. As can be seen in Fig. $1 \mathrm{~A}$, there occurred a remarkable enhancement of the firing rate in the dark soon after the injection. This effeet persisted more than 15 minutes with gradual decline (see Fig. 2). On the other hand, the light-induced response in due course of time was not so impressively affected. As shown in 2 and 3 in Fig. $1 \mathrm{~A}$, the peak frequency of the initial 'on' discharge and subsequent time course of decay to the steady level remained alnost the same in spite of the different levels of preillumination firing rate. The period of post-excitatory inhibition was apparently shortened, but still remained to be perceived.

On the other hand, the effects of strychnine on an off unit were so dramatic. As shown in Fig. $1 \mathrm{~B}$, the firing rate of maintained discharge was enhanced by strychnization. The 'on' inhibition which was manifested by a complete suppression of impulse discharge during illumination prior to strychnization was eliminated except for a brief initial stage. Following the strychnine-resistant initial 'on' inhibition there was another acceleration of discharge. This inversion effect was still observed four minutes after strychnization, so that the general response pattern of the off unit was converted into an on-off type. The 'off' discharge was apparently enhanced.

As for an on-off unit, strychnine elevated the firing rate of maintained 
A
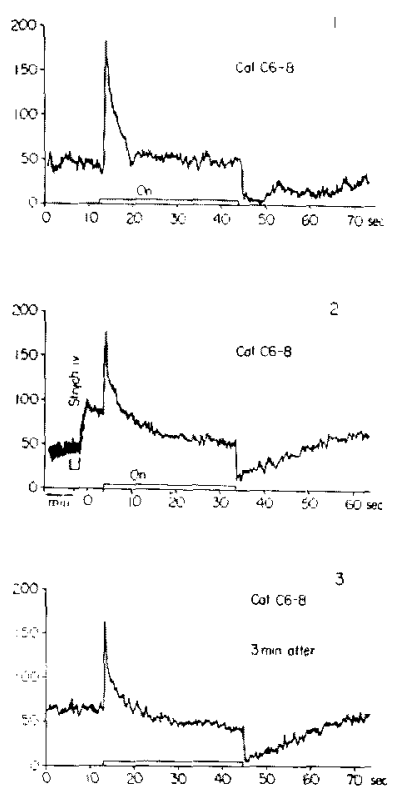

$\mathrm{B}$
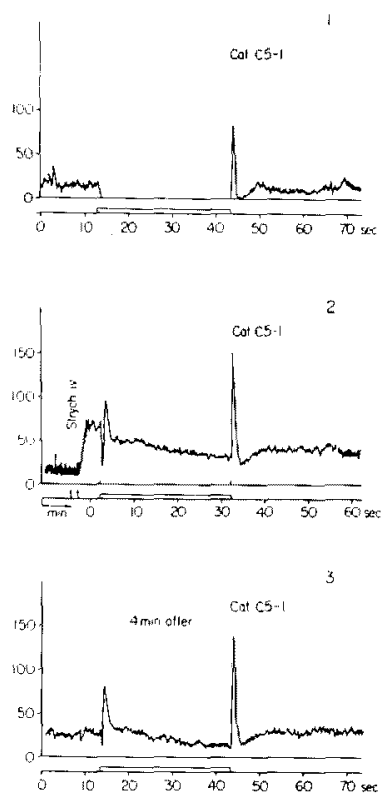

$\mathrm{C}$
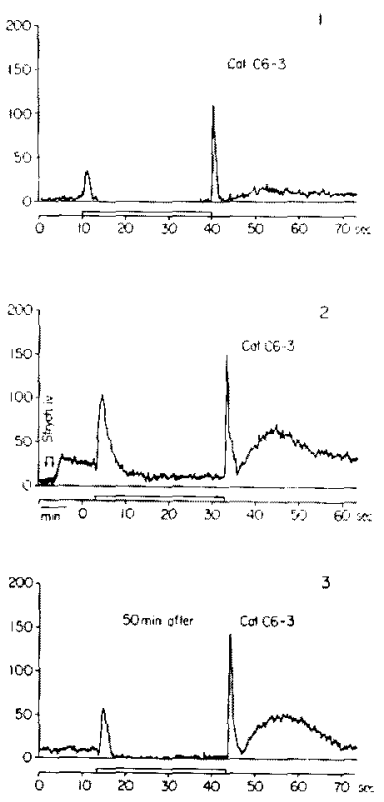

Fig. 1. Strychnine effects on 'on' (column A), 'off' (column B) and 'on-off' (column C) units. Numerals indicate discharge patterns before (1), about 10 sec after (2), and several minutes after (3) strychnization. Arrows connected with horizontal bar show period of intravenous injection of strychaine in a dosis of $0.2 \mathrm{mg} / \mathrm{kg}$. Zero in time scale stands for origin of expanded time scale (sec). Before 0 , time calibration minute is applicable. White bars above time scale indicate 'on' of stimulating light. Ordintes show mean rate of discharge in impulse/ser.

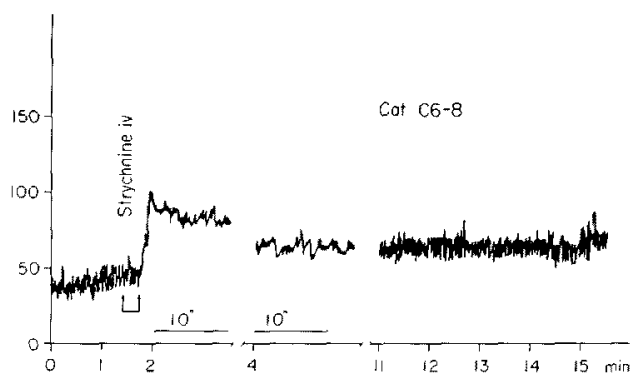

Fig. 2. Time course of strychnine action upon spontaneous discharge of on unit.

This unit is the same as illustrated in Fig. 1A. Recordings of spontaneous discharge were taken one minute after test illumination when effects of illumination wore considered negligible. Time calibration of $10^{\prime \prime}$ is applicable to expanded time scale. Ordinates indicate mean rate of discharge in impulse/sec.

discharge as seen in cases of on and off units and also exaggerated 'on' response with suppression of 'on' inhibition (Fig. 1C). A sharp 'off' response was also enhanced. Another noteworthy finding on this unit is an enhancement of afterdischarge following the 'off' response. The inhibitory phase ensuing on the 'off' response in off and on-off units was not affected by the drug. 
To sum up, strychnine exerted a powerful suppressive action upon 'preexcitatory' inhibition, such as 'on' inhibition of off and on-off units, but little or no effect upon postexcitatory' inhibition, such as 'off' inhibition of an on unit and an inhibitory phase ensuing from the 'off' response of off and on-off units.

According to Eccles' scheme ${ }^{1}$ on inhibitory mechanisms, presynaptic inhibition is insensitive to strychnine applied in convulsive doses which depress postsynaptic inhibition, whereas it is rather susceptible to picrotoxin which is entirely ineffective on postsynaptic inhibition. On this account, picrotoxin tests were carried out on strychnine-insensitive inhibitions.

A unit shown in Fig. 3 is an off unit which was already subjected to strychnization. As described above, the initial 'on' inhibition and postexcitatory 'off' inhibition persisted after strychnization. Tracing A in Fig. 3 illustrates a discharge pattern in response to 30 seconds' illumination fifteen minutes after strychnization. On application of $1 \mathrm{ml}$ of $0.1 \%$ picrotoxin-Ringer solution, the initial 'on' inhibition appeared unaffected, while the 'on' response was enhanced and the postexcitatory 'off' inhibition was eliminated. The maintained discharge did not undergo an appreciable change (Fig. $3 \mathrm{~B}$ ). The effects still persisted five minutes after the injection of picrotoxin (Fig. $3 \mathrm{C}$ ).

Similar suppressive effects of picrotoxin was observed on the postexcitatory inhibition of on units.
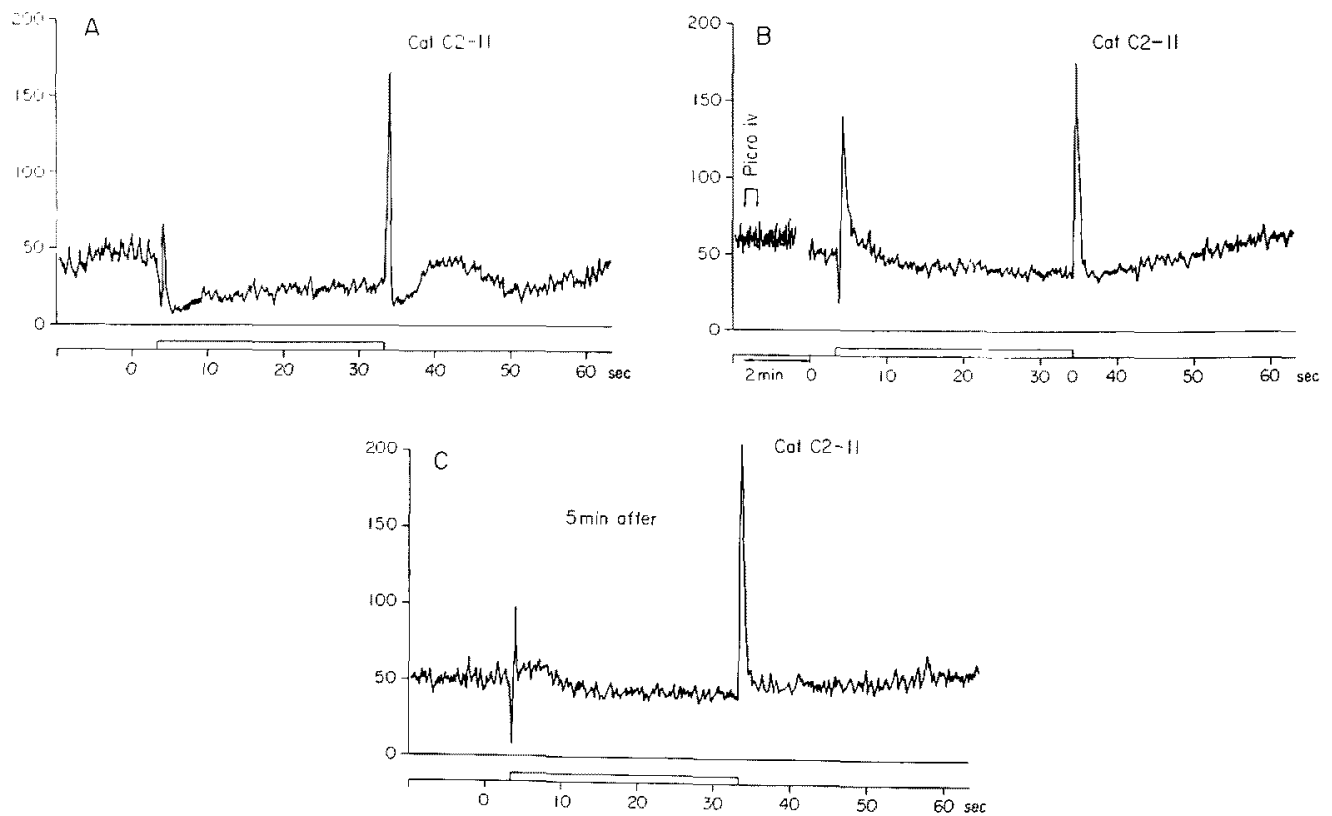

Fig. 3. Picrotoxin effects on off unit after strychnization. A, discharge pattern in response to illumination $15 \mathrm{~min}$ after strychnization $(0.12 \mathrm{mg} / \mathrm{kg}$ i.v.). B, discharge pattern immediately after intravenous administration of picrotoxin ( $1 \mathrm{mg}$ ). C, $5 \mathrm{~min}$ after picrotoxin injection. White bars above time scale indicate 'on' of stimulating light. Ordinates show mean rate of discharge in impulse/seo. 
In the present experiments, thirtcen units (six on, four off and three on-off units) were successfully examined for the action of strychnine and analogous results as described above were obtained. Other six units comprising three on, two off and one on-off, however, did not show any changes in the firing rate of either maintained or light-induced discharge on application of the drugs.

\section{Discussion}

The present results demonstrate that there are two types of inhibition acting in the cat's retinas; strychnine-sensitive and insensitive inhibitions.

The 'on' inhibition observed in off and on-off units was readily eliminated by strychnine. Intracellular recordings from cat's retinal ganglion cells have shown that 'on' inhibition is actually accompanied by hyperpolarization of the cell membrane..$^{\tilde{*}}$ It follows that the 'on' inhibition is strychnine-sensitive postsynaptic inhibition.

Several hypotheses have been advanced to explain an excitatory action of strychnine. Eccles and his collaborators ${ }^{6-10}$ have asserted that strychnine acts only on the postsynaptic inhibitory process and reduces inhibitory postsynaptic potential (IPSP), but does not affect excitatory postsynaptic potential (EPSP) to any extent, thus unmasking the postsynaptic excitatory process. This hypothesis was supported by Kuno ${ }^{11}$ who suggested further effects of strychnine on interneurons to account for the third stage of its action in which a periodic discharge accompanied by a large depolarization wave occurred in spinal motoneurons. On the other hand, Fuortes and Nelson ${ }^{12}$ have placed an emphasis on the contribution of interneurons, maintaining that increased reflex activity of motoneurons under the influence of strychnine results from an increase of excitatory impingement upon motoneurons. More recently, Stefanis and Jasper ${ }^{13}$ bave put forward the inversion hypothesis to the effect that strychnine may not only diminish or abolish the postsynaptic inhibitory potential but also invert it to the depolarizing potential.

Since there is general view that strychnine may act on postsynaptic inhibition. by preventing access of an inhibitory transmitter substance to the receptor sites of the inhibitory subsynaptic membrane, ${ }^{10}$ it may be inferred that the transmitter substance responsible for the postsynaptic inhibitory process in the cat's retina may be identical with that in the central nervous system.

Recently evidence has been provided for the existence of strychnine-resistant postsynaptic inhibition. ${ }^{14-19}$ According to Kellerth and Szumski, ${ }^{18,19}$ strychnineresistant postsynaptic inhibition observed on spinal motoneurons was abolished by picrotoxin; the inhibition was consequently picrotoxin-sensitive. Thus they supposed that strychnine-sensitive, picrotoxin in sensitive inhibition and strychnime-insensitive, picrotoxin-sensitive inhibition were the two main types of inhibition acting on peripherally activated postsynaptic inhibitory mechanisms and that both were different in a transmitter substance involved in their process. In view of such experiments, strychnine-insensitive, picrotoxin-sensitive 
inhibition demonstrated in the present experiments will be interpreted as being postsynaptic in nature. An alternative interpretation, however, is possible from a view-point of presynaptic inhibition which is currently accepted for a wide variety of inhibition. The possibility for presynaptic inhibition has been suggested from morphological findings of presynaptic intereaction in the inner plexiform layer of the vertebrate retina. ${ }^{3,4}$ The present results do not afford evidence in support of one of these alternatives.

Even more complex situation may arise when strychnine-insensitive, picrotoxininsensitive inhibition, which was manifested in the very early stage of the 'on' inhibition, is taken into consideration. Llinas $\mathrm{s}^{20}$ suggested the existence of the third type of postsynaptic inhibition resistant to both strychnine and picrotoxin, in his study on the influence of reticular stimulation on spinal extensor motoneurons. At present it is not certain that such inhibition is a distinct entity or a representation of relative ineffectiveness of picrotoxin in small doses.

Intracellular recordings will promote investigation of further details of synaptic mechanisms of inhibition in the cat's retina.

\section{References}

1) Eocles, J.C. The Physiology of Synapses. Springer Verlag, Berlin-Göttingen-Heidelberg, 1964.

2) Eccles, J.C., Schmidt, R.F. \& Willis, W.D. Pharmacological studies on presynaptic inhibition. $J$. Physiol. (Lond.), 1963, 168, 500-530.

3) Kidd, M. Electron microscopy of the inner plexiform layer of the retina in the cat and the pigeon. J. Anat. (Lond.), 1962, 96, 179-187.

4) Dowling, J.E. \& Boycott, B.B. Neural connections of the retina: Fine structure of the inner plexiform layer. Cold Spring Harbor Symp. Quant. Biol., 1965, 30, 393-402.

5) Wiesel, T.N. Recording inhibition and excitation in the cat's retinal ganglion cells with intracellular electrodes. Nature (Lond.), 1959, 183, 264-265.

6) Eccles, J.C. The Physiology of Nerve Cells. Johns Hopkins Press, Baltimore, 1957.

7) Eccles, J.C., Fatt, P. \& Koketsu, K. Cholinergic and inhibitory synapses in a pathway from motor-axon collaterals to motoneurones. J. Physiol. (Lond.), 1954, 126, 524-562.

8) Coombs, J.S., Eceles, J.C. \& Fatt, P. The specific ionic conductances and the ionic movements across the motoneuronal membrane that produce the inhibitory postsynaptic potential. J. Physiol. (Lond.), 1955, 130, 326-372.

9) Curtis, D.R. The depression of spinal inhibition by electrophoretically administered strychnine. Int. J. Neuropharmacol., 1962, 1, 239-250.

10) Curtis, D.R. The pharmacology of central and peripheral inhibition. Pharmacol. Rev., 1963, 15, 333-364.

11) Kuno, M. Effects of strychnine on the intracellular potentials of spinal motoneurons of the toad. Jap. J. Physiol., 1957, 7, 42-50.

12) Fuortes, M.G.F. \& Nelson, P.G. Strychnine: Its action on spinal motoneurons of cats. Science, 1963, 140, 806-808.

13) Stefanis, C. \& Jasper, H. Strychnine reversal of inhibitory potentials in pyramidal tract neurons. Int. J. Neuropharmacol., 1965, 4, 125-138.

14) Andersen. P., Eccles, J.C., Løyning, Y.\& Voorhoeve, P.E. Strychnine-resistant central inhibition. Strychnine-resistant inhibition in the brain. Nature (Lond.), 1963, 200, 843-845.

15) Crawford, J.M., Curtis, D.R., Voorhoeve, P.E. \& Wilson, V.J. Strychnine-resistant 
central inbition. Strychnine and cortial inhibition. Nature (Lond.), 1963, 200, 845-846.

16) Green, J.D., Mancia, M. \& von Baumgarten, R. Recurrent inhibition in the olfactory bulb. I. Effects of antidromic stimulation of the lateral olfactory tract. $J$. Neurophysiol, 1962, 25, 467-488.

17) Kellerth, J.-O. A strychnine-resistant postsynaptic inhibition in the spinal cord. Acta physiol. scand., 1965, 63, 459-471.

18) Kellerth, J.-O. \& Szumski, A.J. Two types of stretch-activated post-synaptic inhibitions in spinal motoneurones as differentiated by strychnine. Acta physiol. scond., 1966, 66, 133-145.

19) Kellerth, J.-O. \& Szumski, A.J. Effects of picrotoxin on stretch-activated postsynaptic inhibitions in spinal motoneurones. Acta physiol. scand., 1966, 66, 146-156.

20) Llinas, R. Mechanisms of supraspinal actions upon spinal cord activities. Pharmacological studies on reticular inhibition of alpha extensor motoneurons. $J$, Neurophysiol., 1964, 27, 1127-1137. 